\title{
Relaciones interculturales a través de las artesanías. Alcances del Proyecto Rihla
}

Carlos Sánchez de las Heras. Jefe de Servicio de Investigación y Difusión de la Dirección General de Bienes Culturales. Consejería de Cultura. Junta de Andalucía

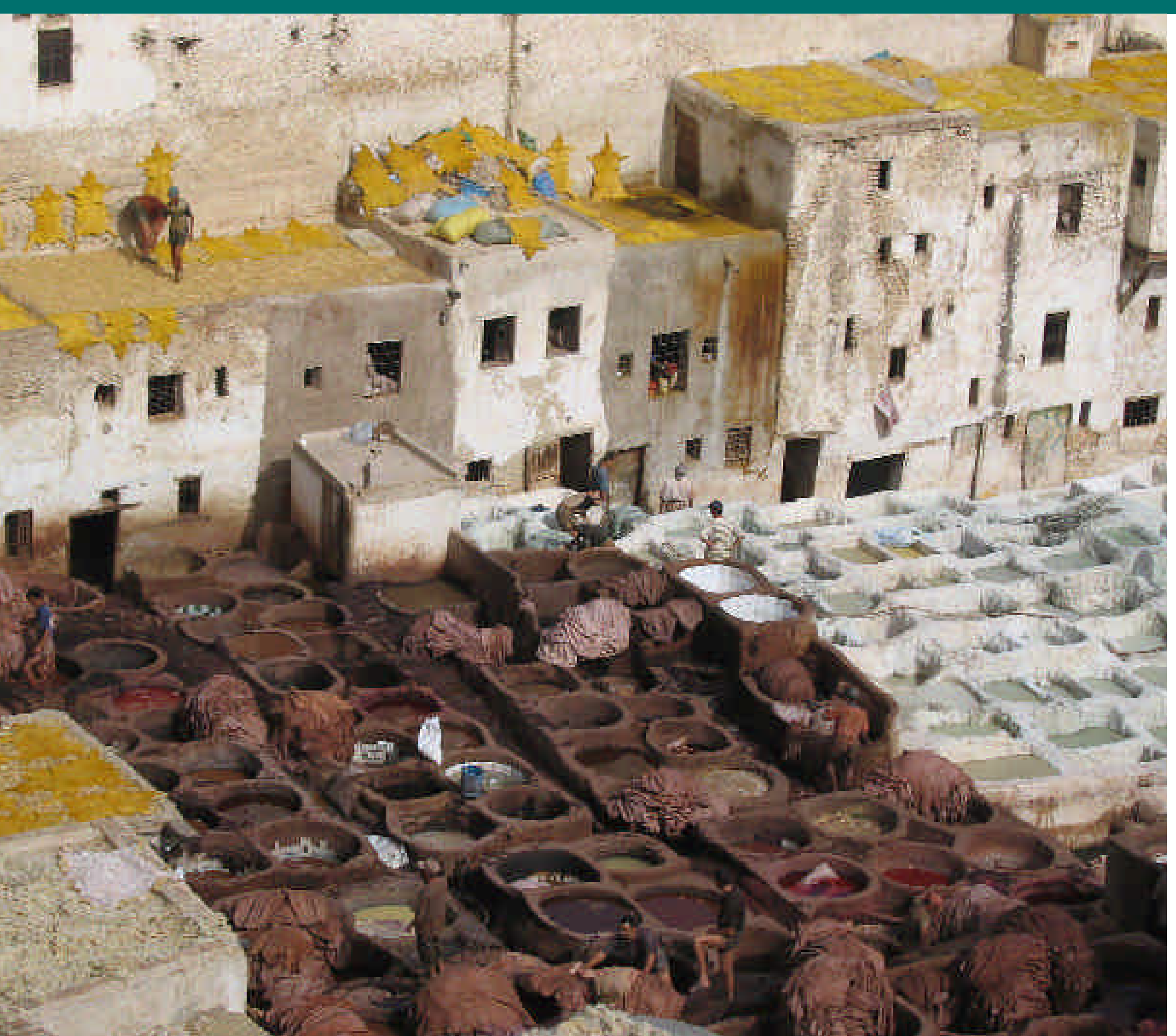




\section{La artesanía ha desempeñado un papel prioritario dentro de las culturas andaluza y norteafricana, cuyos intercambios se reflejan fundamentalmente en las artes decorativas y}

\section{ornamentales}

\begin{abstract}
Resumen
Andalucía y Marruecos comparten un pasado histórico común y pertenecen a un espacio geográfico de características muy similares. Los movimientos migratorios entre las dos orillas han fructificado en diferentes aspectos culturales que pueden ser aprovechados como recursos para el desarrollo socioeconómico de ambas orillas. Entre estos destaca la artesanía -especialmente las artes decorativas y ornamentales-, que ha desempeñado un papel prioritario dentro de las culturas andaluza y norteafricana. Las influencias en este terreno han sido recíprocas, ya que en Andalucía los artesanos de origen musulmán pronto transmitieron sus conocimientos a discípulos hispanomusulmanes y estos a su vez a los cristianos, produciéndose una evolución de las técnicas y los motivos decorativos. Desvelar estos aspectos de la cultura inmaterial que aún hoy persisten entre nosotros y que se configuran como una auténtica herencia cultural común constituye el objetivo del proyecto RIHLA.
\end{abstract}

\section{Palabras clave}

Andalucía I Artesanía I Cooperación I Estrecho de Cibraltar I Herencia cultural I Historia I Itinerarios culturales I Marruecos I Mediterráneo I Migración I Patrimonio inmaterial I Proyecto RIHLA
El sur de España y el norte de Marruecos comparten un pasado histórico común y la pertenencia a un espacio geográfico de características ecológicas muy similares. El futuro que han de gestionar como regiones fronterizas de la Unión Europea y el Mundo Árabe hace especialmente necesario el rescate de las herencias culturales comunes para hacer frente a los actuales desafíos. La idea motriz es que el mestizaje cultural y la permeabilidad entre Andalucía y Marruecos, demostrada históricamente, contienen elementos cuyo conocimiento puede ser valioso para encarar el futuro. Desvelar estos elementos es una tarea necesaria e inaplazable, y uno de los objetivos fundamentales del proyecto RIHLA.

Tras una primera etapa de acciones de cooperación en la que se trataron los centros históricos de influencia islámica y sus elementos muebles e inmuebles más relevantes desde el punto de vista de su preservación como elementos de patrimonio material', se formuló RIHLA, Las Huellas de la Memoriaz. En esta fase del proyecto se pretende orientar los trabajos bajo una óptica antropológica que permita desvelar aquellos aspectos de la cultura inmaterial que aún hoy persisten entre nosotros y que se configuran como una auténtica herencia cultural común.

Nos proponemos descubrir y reconocer todo aquello que todavía compartimos y que cobre finalmente sentido esa frase tan manida que dice que "es más lo que nos une que lo que nos desune", y que algunos utilizan sin mucha convicción. Y sobre todo, podremos concienciar a esa parte de la población andaluza que rechaza irreflexivamente a la inmi-

${ }^{1}$ Para más información sobre el proyecto Red de Centros Históricos de Influencia Islámica en el Sur Peninsular y Norte de Marruecos, consúltese PH32, septiembre de 2000, p. 7.

${ }^{2}$ RIHLA 2 Itinerarios Culturales de Andalucía y Marruecos forma parte de los proyectos de la iniciativa comunitaria de cooperación interregional Interreg III A España - Marruecos. Actúa como Jefe de filas la Consejería de Cultura de la Junta de Andalucía- D.G. de Bienes Culturales. 
gración magrebí, de los importantes vínculos culturales que tiene con ellos, aceptando su integración en nuestro medio social y laboral.

El proyecto RIHLA concuerda con la continua acción política de la Consejería de Cultura de la Junta de Andalucía que contempla el patrimonio desde un enfoque integral. En función de esta perspectiva, los bienes patrimoniales no constituyen sólo recursos aislados y susceptibles de conservación, sino también activos de desarrollo socioeconómico de las ciudades y pueblos en los que se asientan esos bienes. Asimismo, el patrimonio se considera en el marco de un desarrollo equilibrado y de integración entre las regiones fronterizas, en este caso Andalucía y Marruecos.

Con estos presupuestos básicos, y con la convicción de que la mejor manera de conocer y comprender el rico patrimonio arquitectónico y artístico de Al-Andalus es mediante el análisis de aquellos elementos de la memoria que hoy perviven en nuestra vida cotidiana, en nuestras tradiciones y costumbres y en nuestras manifestaciones religiosas y festivas, se propuso el proyecto RIHLA a la Unión Europea.

Las Huellas de la Memoria se aprobó con los contenidos inicialmente previstos, pero con Andalucía como único socio participante, lo que no deja de ser contradictorio tratándose de una iniciativa de cooperación. Tras una cierta perplejidad inicial, entendimos que RIHLA trataría las huellas de una memoria todavía presente a través de unos itinerarios inmateriales, y por tanto transitables por todo el ámbito geográfico de las dos orillas, confundiendo ambos territorios y buscando sus paralelismos e identidades. La preocupación por el conocimiento mutuo y la preservación y conservación de un gran acervo cultural adquiere en nuestros días cada vez más importancia por varias razones: en primer lugar, porque el patrimonio inmaterial corre el peligro de desaparecer; en segundo lugar, porque si siempre existieron lazos y relaciones entre las orillas norte y sur de nuestro mar, los existentes entre Andalucía y el Magreb tienen singular importancia, y ponerlos en valor es cada vez más necesario para llevar a la llamada "sociedad de la comunicación" todo aquello que favorezca la interculturalidad; y tercero, porque gran parte de esa cultura se ha convertido en un motor para corrientes tan poderosas como la del turismo y necesita un tratamiento adecuado.

El proyecto abarca geográficamente toda Andalucía, si bien por ordenanza de la iniciativa Interreg III-A son prioritarias las provincias de Cádiz y Málaga, así como sus provincias limítrofes. En cuanto a Marruecos, aunque su territorio no es elegible a los efectos de intervención directa, se ha considerado importante incluir las poblaciones del norte (Alcazarseguir, Arcila, Tetuán, Tánger, Xauen, Larache y Alcazarquivir) con el fin de estudiar los paralelismos.

RIHLA se articula a partir de nueve itinerarios inmateriales - (1) Paisaje de las dos riberas del Mediterráneo Occidental; (2) Flujos

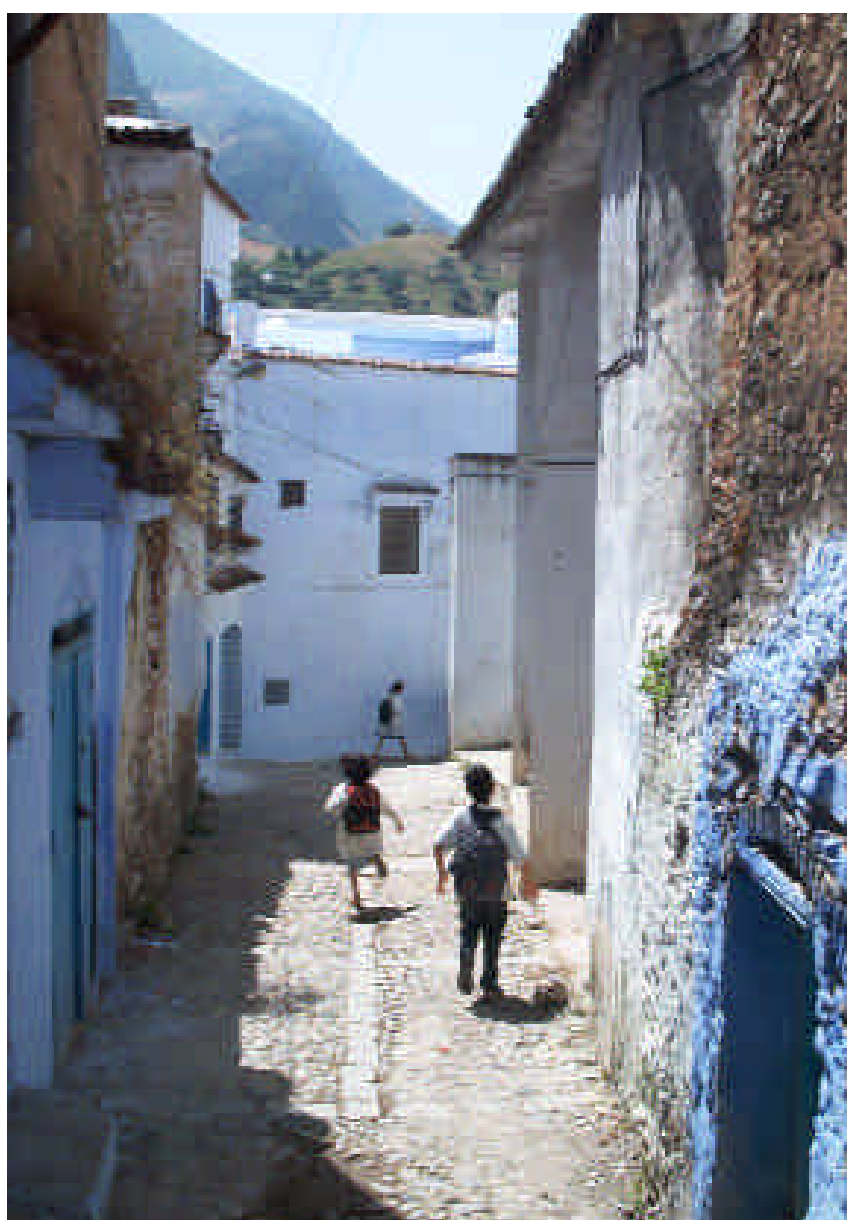

๑ Calle de Xauen / Virginia Luque Gallegos 


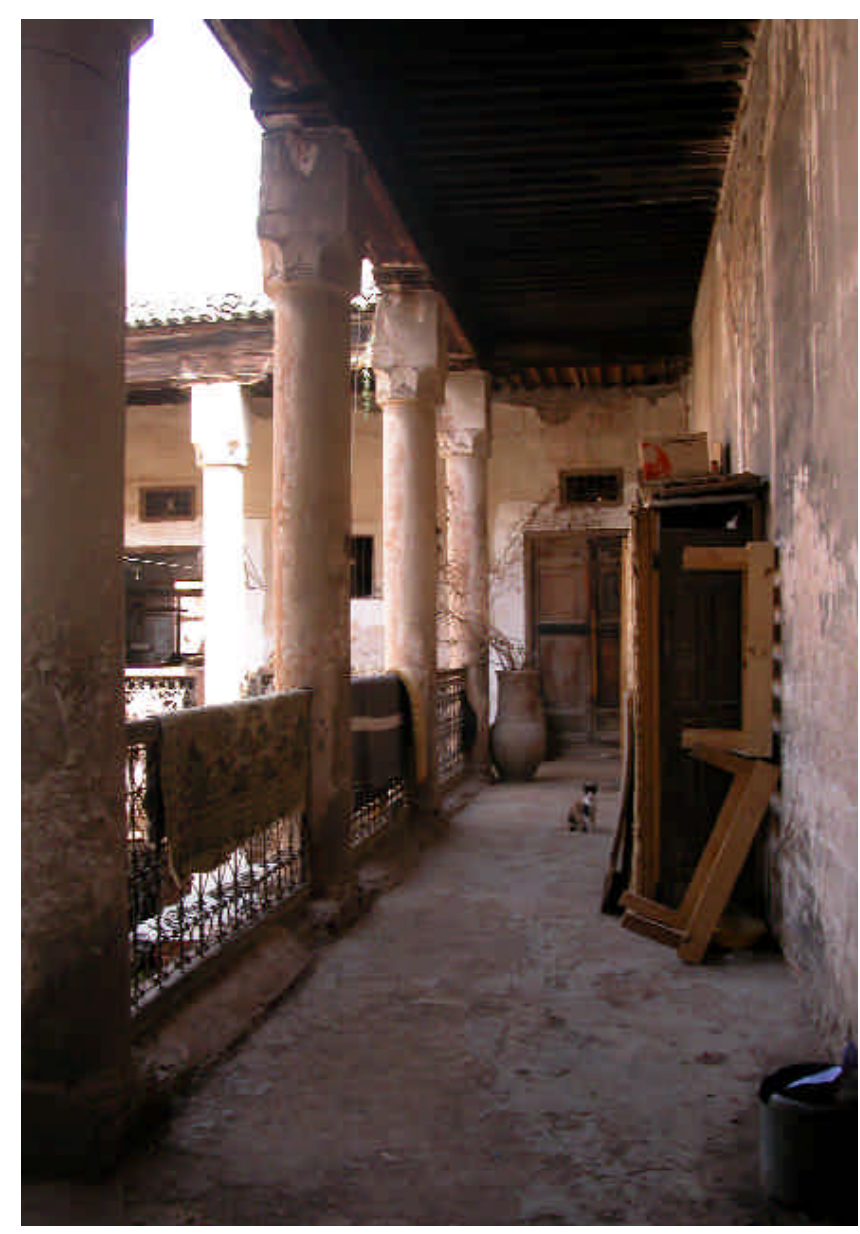

(1) Casa-taller de artesanos. Medina de Marrakech / Lola Caraballo

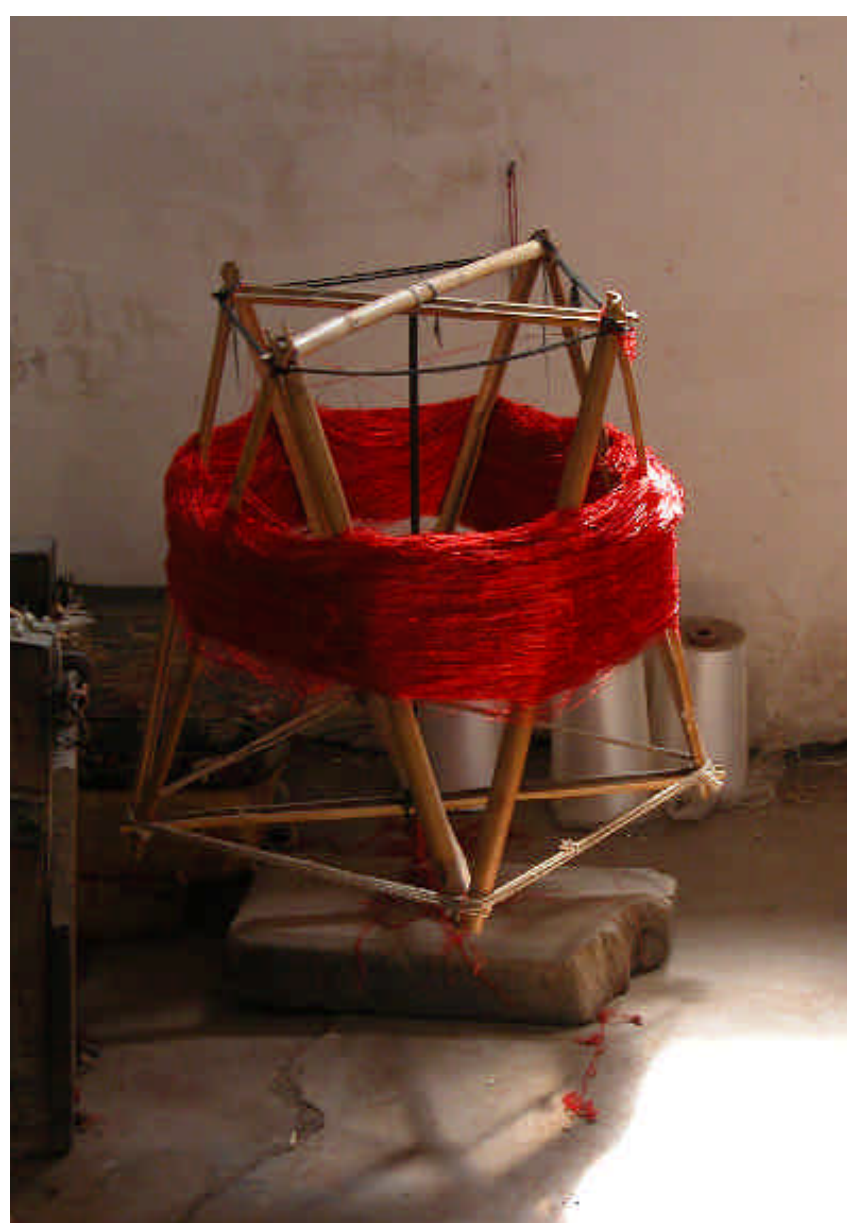

๑ Rueca. Marrakech / Lola Caraballo

\section{Coordinadores y autores del Proyecto} RIHLA

El presente texto ha sido realizado a partir de la documentación generada por la Dirección General de Bienes Culturales para la génesis, aprobación y posterior gestión del proyecto RIHLA, realizado con la colaboración de Rafael Valencia Rodríguez, Antonio Zoido Naranjo y Luis González Tamarit, como coordinadores científicos del proyecto desde la Fundación Averroes, así como de los textos de los diferentes itinerarios cuyos autores son: Paisaje (Juan Francisco Ojeda Rivera, Mostafa Lamrani Alaoui, Águeda A. Villa Díaz y J. Antonio Ojeda Sánchez), Flujos migratorios (Rafael Valencia, Mercedes Jiménez Álvarez, $\mathrm{M}^{a}$ del Carmen González Gila, Alejandro García Sanjuán, Ana Torres, Mouna Ibrahim Sánchez y Fernando Landro), Fiestas, creencias y tradiciones (Antonio Zoido Naranjo, Antonio Basallote Marín, Juan Ramón Artillo Grau), Formas culinarias (Virginia Luque Gallegos), Atuendo (Rocío Plaza Orellana, Luis R. Méndez Rodríguez y Helena Pérez Gallardo), Música (María Valverde), Literatura oral ( $\mathrm{M}^{\mathrm{a}}$ Dolores López Enamorado, Juan Félix Bellido, Eva Bernal y Abderramán Mohamed Manan), Legado lingüistico (Rafael Valencia, Ana Torres García y Ricardo Abad), Artesanías (Eva González Lezcano y Raquel López Rodríguez). 


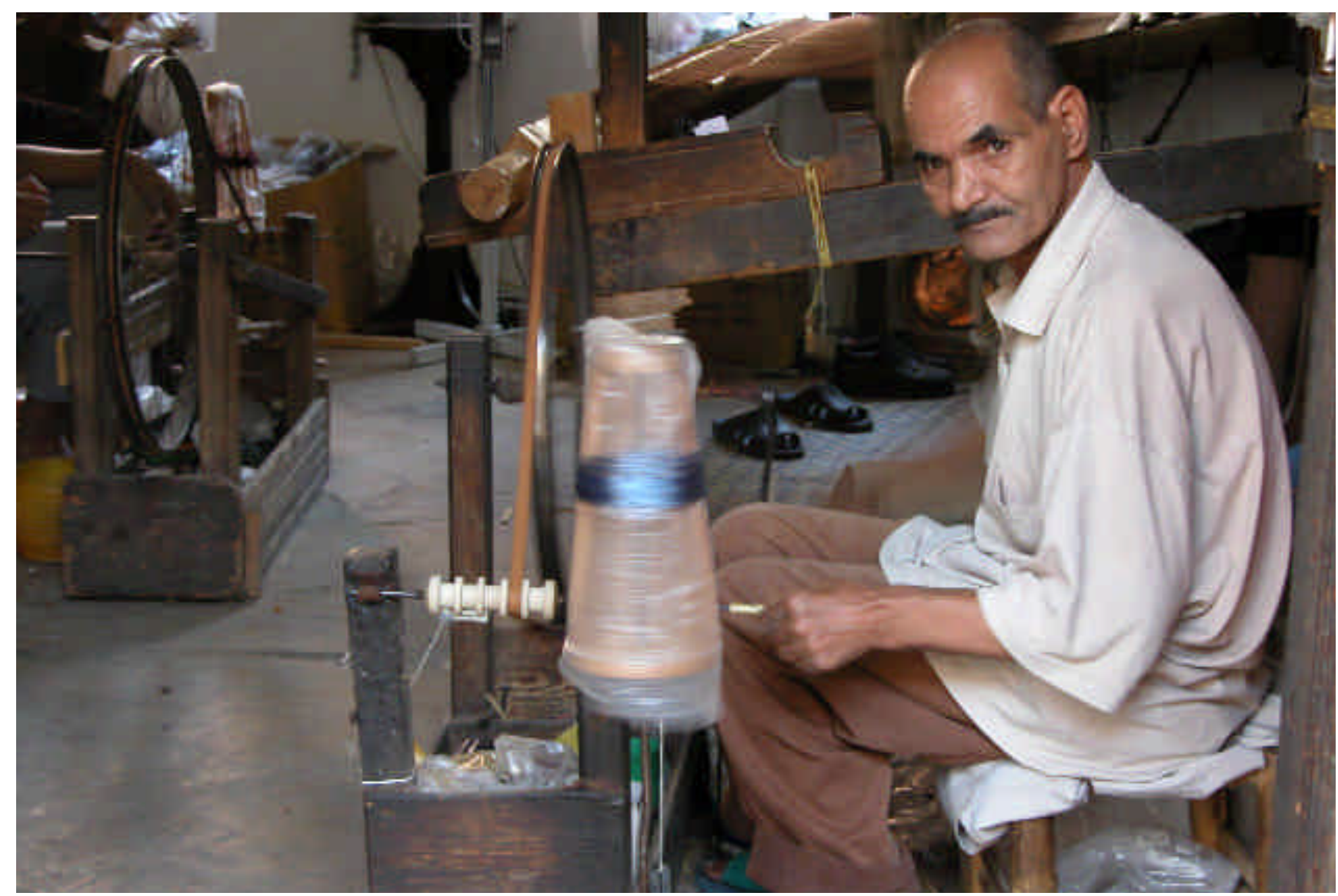

๑ Artesano. Marrakech / Lola Caraballo

migratorios, vínculos y linajes; (3) Fiestas, creencias y tradiciones; (4) Formas culinarias y hábitos alimenticios; (5) El atuendo; (6) La música; (7) Literatura de tradición oral; (8) Legado lingüístico y toponímico; y finalmente (9) Las artesanías- que sirven de instrumento a la valoración de la herencia cultural común. Los movimientos migratorios suponen uno de los elementos más señalados para la génesis de ese legado.

\section{Las artesanías}

El deseo primitivo de proveerse de objetos útiles para el trabajo y el descanso dio paso a técnicas elaboradas y formas depuradas sobre el modo de realizar los objetos. Estas técnicas y formas relacionaron a los pueblos y, en especial, a los que vivían en regiones cercanas y en condiciones climáticas similares, donde las materias primas son aproximadamente las mismas y donde la historia unió o enfrentó.

La artesanía ha desempeñado un papel prioritario dentro de las culturas andaluza y norteafricana, cuyos intercambios se reflejan fundamen- talmente en las artes decorativas y ornamentales. Tales intercambios se efectuaban en buena medida a través de los viajes y el comercio de los mercaderes andalusíes por todo el Mediterráneo. Afectaban tanto a la transmisión de objetos como a las técnicas, estilos y motivos. Estos productos fácilmente transportables hicieron posible una rápida intro ducción en el nuevo mercado.

Las influencias fueron recíprocas a una y otra orilla del Estrecho de Gibraltar, ya que en Andalucía los artesanos de origen musulmán pronto transmitieron sus conocimientos a discípulos hispano-musulmanes y estos a su vez a los cristianos, produciéndose una evolución de las técnicas y los motivos decorativos. Un buen ejemplo son los tejidos realizados con seda, introducidos por los musulmanes y desarrollados por artesanos malagueños que le dieron fama internacional. En el norte de Marruecos también se produjo la llegada de artesanos andalusíes cuya consecuencia fue la implantación de nuevas formas de trabajar los materiales. Estas relaciones interculturales han pervivido a lo largo de los siglos como puede observarse en la influencia que la escuela popular andaluza de forja ha ejercido en la del norte de Marruecos a partir del siglo XVII. 
A pesar de un período de crisis provocado por la industrialización del sector artesano, se mantienen los oficios del cuero, metal, madera, telares y la producción alfarera en pequeños talleres familiares, motivado en muchos casos por la demanda turística. La transmisión de estos conocimientos no sólo se produce de padres a hijos sino que se realiza también a través de escuelas locales de artesanía como la Escuela de Artes y Oficios Tradicionales de Tetuán o la escuela textil La Madraza de Málaga.

Hoy por hoy la artesanía es parte inequívoca del patrimonio cultural y de la historia de todos los pueblos. En el norte de Marruecos y en Andalucía existe una conciencia común por la protección de estas formas de expresión popular, debilitadas en gran medida por los profundos cambios en los sistemas de producción y en las pautas de consumo, con consecuencias diversas. Entre ellas, la sustitución de los objetos de consumo, el abaratamiento de costes y la reducción de la mano de obra. La artesanía norteafricana sigue muy presente en la vida diaria mientras que en Andalucía, cada vez más, estos productos son consumidos por una minoría en busca de la calidad y la originalidad, ya que cada objeto es único y por tanto irrepetible.

La mayoría de los artesanos de uno y otro lado se agrupa en asociaciones, federaciones o cooperativas para la protección y la difusión de sus productos. Ejemplos como la Federación de Artesanos de Andalucía, Cooperative de Tisserands Artissanal de Chaouen, la Asociación Granadina Empresarial de Mujeres Artesanas, Les Doigts D'or (asociación de artesanas), la Union Nationale des Femmes Marrocaines, la Asociación de Artesanos de las Alpujarras y la Asociación Ittihad Chamali, entre otras. Estas agrupaciones, junto con algunas instituciones públicas, luchan por salvaguardar el Patrimonio Cultural Artesanal. Las vías para ello son muy diversas, entre ellas la cumplimentacíón de un registro de artesanos, la organización de eventos de ámbito local, provincial o nacional en los que los artesanos de sus agrupaciones exponen sus productos, publicaciones, jornadas y congresos, etc.

El principal espacio donde se desarrollan las artes populares son los zocos o mercados. El zoco marroquí es complejo tanto es su estructura como en su funcionalidad. Su origen se remonta a tiempos de la conquista romana, en la Mauritania Tingitana. Se trataba de mercados fronterizos entre tribus rurales, junto a vías de comunicación y alejados de las aglomeraciones urbanas. El sistema de trueque o intercambio sería la forma más habitual de la transacción comercial. En España, los zocos de la época de Al-Andalus, como los de Huelva y Málaga, nos ofrecían tanto las tendencias artesanales de un determinado sitio en un determinado momento, en función del predominio de algunos oficios artesanales, como los diferentes gustos de la época. En el campo abierto las tiendas de telas se instalaban rápidamente en círculo, y bajo su sombra se extendían las mercancías. En los zocos urba-

\section{En el norte de Marruecos y en Andalucía existe una conciencia común de protección de las artesanías, debilitadas en gran medida por los profundos cambios en los sistemas de producción y en las pautas de consumo}

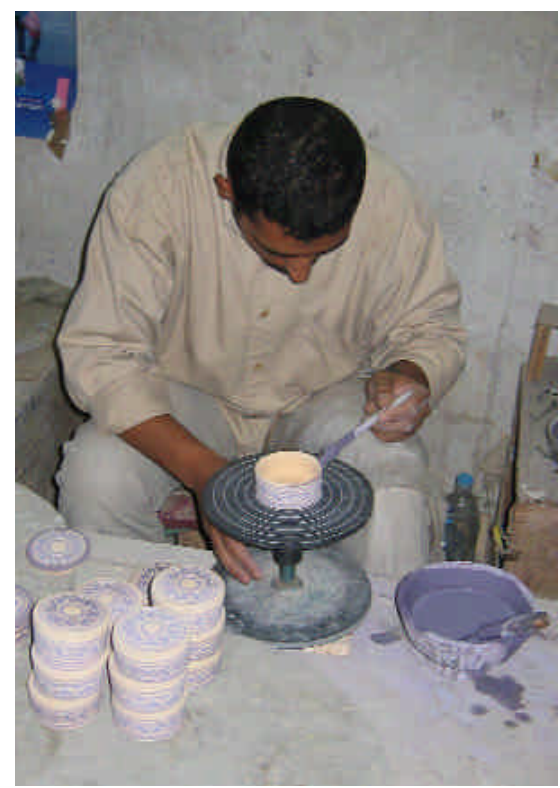

(1) Gremio de los ceramistas. Fez (Marruecos) / Antonio Martín Pradas 


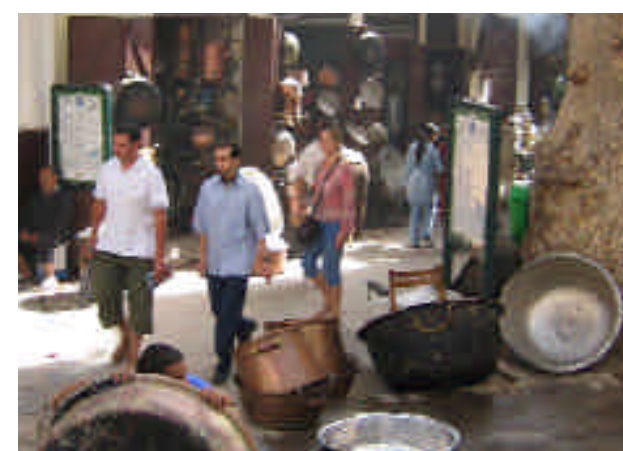

(1) Gremio de los caldereros. Fez (Marruecos) / Antonio Martín Pradas

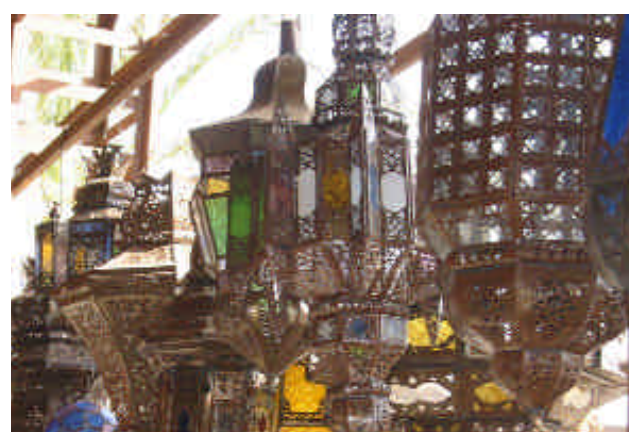

( Herrería. Marrakech (Marruecos) / Isabel LuQue Ceballos nos las tiendas se instalaban en la medina, aunque aquí se produjo una dispersión de oficios debido a que algunos de ellos, como la artesanía del cuero, de la madera y el teñido de tejidos, se realizaban en las afueras de la ciudad por ser actividades molestas.

La herencia o el destino marcaron la trayectoria de muchas gentes andalusíes cuyos oficios seculares pasaron de padres a hijos, revelando una especialización de tipo étnico y religioso a la vez.

Los oficios artesanales mas destacados dentro de estos zocos urbanos fueron aquellos grupos dedicados a los textiles (pañeros, sederos, ropavejeros, tejedores, tintoreros y blanqueadores de telas), cuero (zapateros, alcorqueros, peleteros y curtidores), alfarería, metal y madera (alfareros, herreros, carpinteros y aserradores).

Dentro de los oficios que se desarrollaban en el zoco, el orfebre, el vendedor de tejidos y el artesano de la seda eran los más codiciados. Los comerciantes de tejidos y bordados gozaban también de gran prestigio social. En las relaciones de los oficios del zoco había una abundancia de los vinculados a los tejidos y vestimenta. Se importaban tejidos de Persia y Túnez, pero la mayoría se tejían en Almería o Málaga con las técnicas de Persia, Irak o Antioquia. Destacaban los tejidos con filamentos de oro y bordados de madreperla, fabricados en Al-Andalus. En la Granada nazarí, la producción de seda granadina y la explotación de su industria fue de vital importancia en el desarro llo de la economía de este reino.

En el presente se continúa la tradición del zoco en el norte de Marruecos. En las medinas de ciudades como las de Tánger o Tetuán, todos los días se pueden adquirir los más variados productos en pequeñas tiendas o talleres, a la manera de lo que ocurría en las ciudades hispanomusulmanas, que se abren a las estrechas calles o tenderetes. La estructuración funcional de las medinas se produce en muchos casos en función de los oficios que allí se desarrollan, conservándose espacios dedicados a los ebanistas, a los artesanos del cuero, etc., de manera similar a lo que ocurría en Andalucía durante la Edad Media. Esta característica deja huella visible en la estructura urbana de las medinas. Los artesanos de la madera, del metal, del cuero, de la cerámica y de las alfombras constituyen el artesanado tradicional. Se localizan en las ciudades, único espacio que puede absorber su producción, sufriendo desde hace varias décadas una lamentable caída, ante la avalancha de los modernos objetos de plástico y materiales sintéticos. Hoy en día vuelven a resurgir, apoyados en las escuelas de artesanía, gracias a la demanda turística e interior, que propugna una vuelta a las tradiciones sociales y artesanales.

Además, en Marruecos se realizan una serie de zocos semanales que no se limitan sólo al perímetro de las ciudades o pueblos, sino que también se encuentran espacios habitados en el campo. Se desarro- 
llan durante todos los días de la semana exceptuando los viernes, que es el día sagrado de la oración. Las poblaciones cercanas entre sí celebran estos encuentros en días diferentes de la semana, evitando la coincidencia. Los que han sobrevivido al paso del tiempo son especialmente los que están situados próximos a las carreteras principales, ya que tienen un acceso más fácil y cómodo, mientras los localizados entre pueblos han ido perdiendo importancia o desapareciendo. En este tipo de reuniones comerciales no se sabe muchas veces lo que se puede encontrar, ya que los campesinos y artesanos acuden con el material del que disponen en ese momento. Con e tiempo, y en torno a esta celebración semanal, se han creado poblados que toman el nombre del zoco y a veces incluso de los productos que lo caracterizaban, así por ejemplo Khemis-Boujadine, situado cerca de Ksar el Kbir significa "el jueves, del de las cabras", Telata de Bini Ider "el martes de Beni Ider", etc.

En Andalucía pervive, de manera un tanto lejana, el recuerdo de los zocos semanales en los mercadillos que una vez cada siete días se ins- talan en ciudades y pueblos, aunque en estos la venta de artesanía ha dejado paso a la de ropa y zapatos confeccionados de forma industrial. Por otro lado, se plantean ferias de artesanía, casi siempre con carácter anual, muchas veces promovidas por los poderes públicos para potenciar la venta de estos productos, como forma de promocionarlos y evitar que su producción caiga en el olvido.

En los últimos años se están popularizando la organización de mercados que giran en torno a la temática andalusí, con la venta de objetos hechos a mano y con decoración inspirada en esta época, además de comida de tradición islámica, como forma de desarrollar el turismo y de mantener las raíces de muchos pueblos andaluces como Almonaster la Real (Huelva) u otros de la Axarquía malagueña.

El itinerario de las artesanías se compone de diversos estudios en profundidad sobre la cerámica, los textiles, el cuero, el metal y la madera, no sólo desde el análisis del pasado y presente común, sino también en cuanto a su aplicación a la vida diaria.

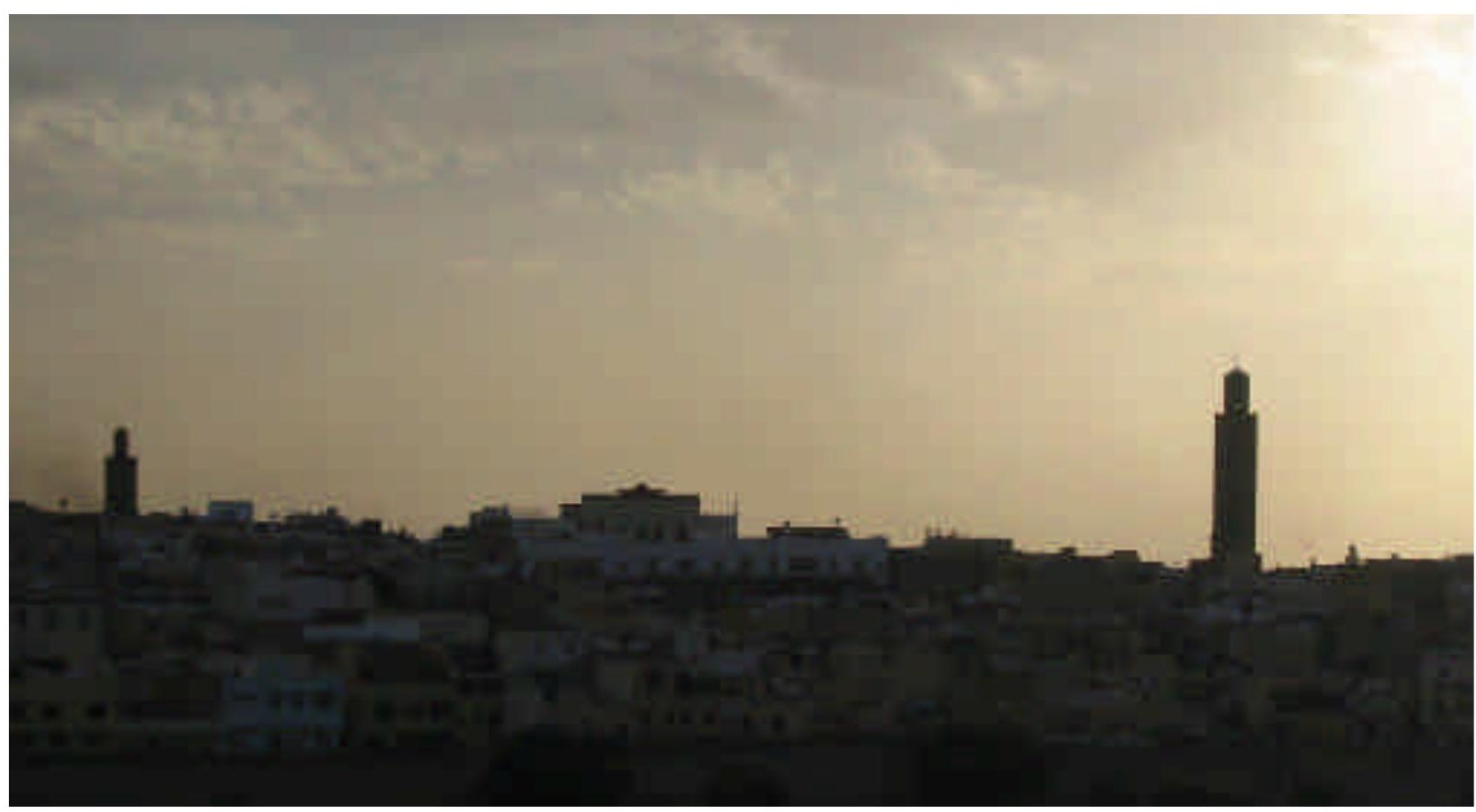

